\title{
Proteção social e produção do cuidado a travestis e a mulheres trans em situação de rua no município de Belo Horizonte (MG)
}

\author{
Social protection and production of care for transvestites and \\ transgender women in homeless situation in the city of Belo \\ Horizonte ( $M G)$
}

Lindalva Guimarães Mendes', Alzira Oliveira Jorge ${ }^{\mathbf{2 , 3}}$, Flávia Bulegon Pilecco²

DOI: 10.1590/0103-11042019S808

RESUMO Esta pesquisa qualitativa objetivou identificar como se dá a proteção social e a produção do cuidado a travestis e a mulheres trans em situação de rua nas políticas públicas de saúde e de assistência social no município de Belo Horizonte (MG), a partir da percepção dessas pessoas. Os instrumentais utilizados para coleta de dados foram observação participante, entrevistas semiestruturadas e em profundidade e técnica do grupo focal. Os dados demonstraram que as entrevistadas conhecem e acessam vários serviços do Sistema Único de Saúde (SUS) e do Sistema Único de Assistência Social (Suas). Entretanto, estes não estão alinhados às suas diversidades e singularidades e (re)produzem violências. A atitude de acolhimento de alguns profissionais dos serviços apareceu como indicativo de bom atendimento. Porém, foram relatadas situações de violações de direito a que estão submetidas no cotidiano dos serviços. As principais violências relatadas se relacionam com os critérios e regras de funcionamento, com a falta de privacidade, discriminação e assédio sexual. Este estudo reafirma a importância e a necessidade das políticas e serviços serem pensados e implementados na lógica da construção coletiva, de escuta e diálogo com esses sujeitos de direitos, respeitando as especificidades de suas trajetórias e demandas.

PALAVRAS-CHAVE Pessoas em situação de rua. Transexualidade. Violência. Vulnerabilidade social. Política pública.

ABSTRACT This qualitative research aimed to identify how social protection and the production of care
for transvestites and transgender women in homeless situation are given in the public policies of health and
social assistance in the city of Belo Horizonte (MG), based on the perception of those people. The instruments
used for data collection were participant observation, semi-structured and in-depth interviews, and the focus
group technique. The data showed that the interviewees know and access various services of the Unified
Health System (SUS) and the Unified Social Assistance System (Suas). However, these are not aligned with
their diversity and singularities and (re)-produce violence. The embracing attitude of service professionals
appeared as an indicative of good service. However, situations of violations of the right to which they are
subjected in the daily life of the services have been reported. The main reported violence relates to the crite-
ria and rules of operation, lack of privacy, discrimination, and sexual harassment. This study reaffirms the
importance and necessity of policies and services to be thought and implemented in the logic of collective
construction, listening and dialoguing with these subjects who have rights, respecting the specificities of
their trajectories and demands. Belo Horizonte - Belo Horizonte (MG), Brasil. lindagmendes18@gmail.com

2 Universidade Federal de Minas Gerais (UFMG),

Faculdade de Medicina

- Belo Horizonte (MG),

Brasil.

${ }^{3}$ Hospital Risoleta

Tolentino Neves - Belo

Horizonte (MG), Brasil.

KEYWORDS Homeless people. Transsexuality. Violence. Social vulnerability. Public policy. 


\section{Introdução}

Historicamente, as políticas sociais visam responder às demandas advindas das relações contraditórias determinadas pelas lutas de classes, raça, gênero e etnia. Apesar de não superarem a desigualdade, pode-se dizer que as políticas públicas alteram o padrão de distanciamento entre as classes sociais na medida em que instituem sistemas de proteção social'.

A partir da Constituição de 1988, configura-se, no Brasil, um cenário no qual as políticas sociais entraram em ascensão, graças a um processo de ampliação da cobertura dada aos direitos sociais. Assim, o sistema de proteção social passou a ser organizado a partir do tripé das políticas de previdência social, assistência social e saúde. No campo da política de assistência social, a proteção social se efetiva por meio das seguranças que essa política se propõe a afiançar, alicerçada na oferta de serviços e benefícios socioassistenciais. Essas seguranças são: da acolhida, do convívio familiar, da sobrevivência e renda e do desenvolvimento de autonomia ${ }^{2}$. A discussão da categoria cuidado, no campo da saúde pública no Brasil, tem sido feita por vários autores, entre eles, o médico sanitarista Merhy ${ }^{3}$ que destaca a complexidade que permeia as práticas de saúde relacionada com o cuidado por se basear, necessariamente, em uma perspectiva relacional entre sujeitos, profissional da saúde e usuário.

Segundo Scott ${ }^{4}$, os conceitos relacionados com o gênero, uma vez estabelecidos como um conjunto de referências e normas, estruturam tanto a percepção quanto a organização concreta e simbólica das relações sociais. Dessa forma, pode-se dizer que as convenções hegemônicas que associam o sexo biológico à identidade de gênero regulam e produzem mecanismos de coerção e submissão a padrões normatizados socialmente o que, além de gerar diferentes posições de poder na vida em sociedade, conduzem ou podem conduzir a situações de vulnerabilidade social ${ }^{5,6}$.

A existência de pessoas vivendo nas ruas é inerente ao espaço urbano, ao modo de produção e ao fortalecimento das cidades como espaço no qual as pessoas passam a viver e a desenvolver suas atividades ${ }^{7}$. Para Foucault ${ }^{8}$, o fenômeno social situação de rua deve ser compreendido a partir do reconhecimento das interconexões nas relações de poder entre as experiências pessoais de vida e as dinâmicas sociais da vida urbana, da ocupação dos espaços, do mundo e do mercado de trabalho e da influência do Estado.

Não há, no Brasil, dados oficiais sobre o contingente de pessoas em situação de rua. Em 2015, o Instituto de Pesquisa Econômica Aplicada (Ipea) utilizou-se de dados disponibilizados por 1.924 municípios via Censo do Sistema Único de Assistência Social (Censo Suas); e, após tratamento estatístico, estimou que existiam cerca de 100 mil pessoas em situação de rua no país 9 . Também a magnitude da população de travestis e transexuais não é conhecida, uma vez que tanto no Censo Demográfico, que é realizado a cada 10 anos pelo Instituto Brasileiro de Geografia e Estatística (IBGE), quanto em pesquisas com periodicidade anual, como a Pesquisa Nacional por Amostragem de Domicílios (PNAD), não existem perguntas referentes à identidade de gênero ${ }^{\mathbf{1 4}}$. Entende-se que essas ausências prejudicam a implementação de políticas públicas e reproduzem a invisibilidade social destas populações no âmbito das políticas sociais.

Assim, entendendo que travestis e mulheres transexuais que vivem em situação de rua são pessoas em conjuntura de vulnerabilidade e duplamente excluídas socialmente, este estudo foi desenvolvido tendo como objetivo identificar as dificuldades vivenciadas e as estratégias utilizadas por elas diante dessas dificuldades, e investigar quais as percepções dessas pessoas sobre os serviços do Sistema Único de Saúde (SUS) e do Sistema Único de Assistência Social (Suas) no município de Belo Horizonte (MG).

\section{Metodologia}

A abordagem utilizada para desenvolvimento deste estudo foi da pesquisa qualitativa. Os locais da coleta de dados foram ruas e praças 
da cidade, ponto de prostituição de travestis e mulheres transexuais, equipamentos públicos e casa de uma entrevistada. Ao longo do percurso para fazer a coleta de dados, foram encontradas dificuldades que exigiram flexibilidade e mudanças nas estratégias de aproximação e mobilização do público-alvo. Somente após estabelecimento de vínculo de confiança com duas pessoas que se tornaram informantes-chave, foi possível acessar locais e pessoas disponíveis para participar do estudo.

Os instrumentais utilizados foram a observação participante, entrevistas semiestruturadas e em profundidade e técnica do grupo focal. Para realização do grupo focal e das entrevistas, foi desenvolvido um roteiro que abordou a trajetória das entrevistadas desde quando ainda moravam com suas famílias, a saída de casa, o dia a dia nas ruas, quais serviços das políticas de saúde e de assistência social conheciam e acessavam, além da avaliação e sugestões para melhoria desses serviços.

Os sujeitos da pesquisa foram 12 travestis e mulheres trans acima de 18 anos, vivendo em situação de rua ou com histórico de situação de rua. Das 12 participantes, 3 foram apenas observadas, e 9 foram entrevistadas ou participaram do grupo focal. O grupo focal foi realizado com 5 pessoas, em um abrigo público para mulheres onde algumas delas estavam acolhidas. As entrevistas e o grupo focal foram gravados e totalizaram 5 horas e 30 minutos de áudio que foram transcritos na íntegra, além do registro no diário de campo das observações e de duas entrevistas.

Os dados foram analisados por meio da técnica de Análise de Conteúdo proposta por Bardin ${ }^{10}$; e os resultados, organizados em cinco categorias: trajetórias de vida; vida nas ruas; conhecimento e acesso aos serviços do SUS e do Suas; sugestões para melhoria dos serviços e empoderamento e perspectivas. As especificações dessas categorias serão detalhadas na seção seguinte.

Para a execução da pesquisa, foram observadas as orientações da Resolução de $n^{\circ} 510 / 2016$ do Conselho Nacional de Saúde. O projeto foi aprovado no Comitê de Ética em Pesquisa da Universidade Federal de Minas Gerais (Coep/UFMG), sob $\mathrm{n}^{0} 1140812.1 .0000 .5149$, e as participantes assinaram o Termo de Consentimento Livre e Esclarecido, após serem informados da confidencialidade dos dados coletados para a pesquisa.

\section{Apresentação e discussão dos resultados}

As pessoas entrevistadas tinham idades que variaram de 19 anos a 61 anos, sendo a média de 35 anos. A faixa etária das pesquisadas por Kulick ${ }^{11}$ e Benedetti12 situava-se entre 17 anos e 26 anos e entre 20 anos e 30 anos, respectivamente. Esses autores salientaram que as travestis acima de 40 anos têm dificuldades para se manterem com a prostituição e muitas falecem ainda jovens em função de complicações relacionadas com o Vírus da Imunodeficiência Humana/ Síndrome da Imunodeficiência Adquirida (HIV/Aids) ou vítimas de violência.

Embora a amostra deste estudo seja pequena, observa-se uma grande amplitude de faixa etária e uma idade média apontando para um grupo de mulheres mais envelhecidas, e que conseguiram sobreviver no espaço da prostituição, diferentemente de outros estudos realizados. Essa perspectiva traz implicações para o poder público para a oferta de serviços que garantam proteção social, considerando seus agravos de saúde e uma rede de proteção familiar e comunitária frágeis.

Para facilitar a ligação entre as interlocutoras e suas falas, optou-se por apresentar no quadro 1 um resumo de algumas características sociodemográficas das nove pessoas entrevistadas. Todos os dados e informações são autodeclarados, e foram utilizados pseudônimos a fim de preservar as identidades das entrevistadas. 
Quadro 1. Dados sociodemográficos das participantes entrevistadas e do grupo focal

\begin{tabular}{|c|c|c|c|c|c|c|}
\hline Pseudônimo & Idade & $\begin{array}{l}\text { Identidade } \\
\text { de gênero }\end{array}$ & Cor & Escolaridade & $\begin{array}{l}\text { Tempo em situação } \\
\text { de rua }\end{array}$ & $\begin{array}{l}\text { Situação em relação à situação } \\
\text { de rua por ocasião da pesquisa }\end{array}$ \\
\hline Sandra & 37 & Travesti & Parda & $\begin{array}{l}\text { 8a série Ensino } \\
\text { Fundamental } \\
(E F)\end{array}$ & 9 anos & $\begin{array}{l}\text { Moradia provisória em abrigo } \\
\text { institucional }\end{array}$ \\
\hline Sabrina & 61 & $\begin{array}{l}\text { Mulher } \\
\text { transexual }\end{array}$ & Branca & 4ํsérie EF & $\begin{array}{l}\text { Episódios intermi- } \\
\text { tentes desde } 16 \text { anos }\end{array}$ & Mora com familiares \\
\hline Monete & 30 & Travesti & Parda & 7a série EF & $\begin{array}{l}\text { Não foi possível } \\
\text { saber }\end{array}$ & Mora na rua \\
\hline Amanda & 19 & Travesti & Negra & 8asérie EF & 7 meses. & Mora na rua \\
\hline Cleo & 26 & Travesti & Morena & 8a série EF & 2 anos & $\begin{array}{l}\text { Moradia provisória em abrigo } \\
\text { institucional }\end{array}$ \\
\hline Mary & 40 & Travesti & Parda & 7a série EF & 3 anos & $\begin{array}{l}\text { Moradia provisória em abrigo } \\
\text { institucional }\end{array}$ \\
\hline Dafiny & 35 & Travesti & Branca & 7a série EF & 3 anos & Pernoite em Abrigo \\
\hline Milla & 25 & $\begin{array}{l}\text { Mulher } \\
\text { transexual }\end{array}$ & Preta & 8a série EF & 1 mês & Pernoite em Abrigo \\
\hline Francis & 42 & Travesti & Branca & $\begin{array}{l}\text { Nível superior } \\
\text { incompleto }\end{array}$ & $\begin{array}{l}\text { Episódios intermi- } \\
\text { tentes entre } 2007 \\
\text { e } 2014\end{array}$ & Aluguel social \\
\hline
\end{tabular}

Fonte: Dados primários, elaborados pela autora a partir das entrevistas e grupo focal realizados em Belo Horizonte, outubro de 2017 a fevereiro de 2018 .

Os demais resultados serão apresentados por meio das categorias: trajetórias de vida; vida nas ruas; conhecimento e acesso aos serviços do SUS e do Suas; sugestões para melhoria dos serviços; empoderamento e perspectivas. Para apresentação das falas, não nos ativemos às normas da linguagem culta, e as falas foram transcritas exatamente da forma como foram ditas, inclusive quando elas se referiram a si próprias no gênero gramatical masculino.

\section{a) Trajetórias de vida}

As histórias de vida narradas têm em comum, e quase na mesma sequência, conflitos familiares relacionados com as questões de gênero, seguidos pela saída de casa, prostituição e situação de rua.

O processo de transição, ou seja, as práticas para transformar o corpo por meio do cuidado com as unhas e cabelos, roupas, uso de hormônios e aplicação de silicone, deu-se sem acompanhamento ou orientação médica, corroborando os achados de Kulick ${ }^{11}$ e Benedetti12.
A idade em que elas iniciaram esse processo variou de 12 anos a 16 anos, quando ainda moravam com a família:

Quando eu tinha 12 anos eu sabia que eu não gostava de menina, eu queria ser elas né? ... então tudo foi se colocando na hora certa e com 14 eu já sabia o que era ser travesti. Então com 15 anos eu me assumi [...], eu nem fui gay, eu já passei para travesti, pra travestido né?. (Francis).

A pesquisa realizada pelo Núcleo de Direitos Humanos e Cidadania LGBT da Universidade Federal de Minas Gerais (NUH/UFMG), entre 2011 e 2015, com 141 travestis e mulheres transexuais que exerciam trabalhos sexuais no município de Belo Horizonte - Projeto Trans, mostrou que apenas $7 \%$ das entrevistadas iniciaram o processo transexualizador no SUS ${ }^{13}$. Segundo Benedetti ${ }^{12}$, os efeitos colaterais desconfortáveis e prejudiciais do uso indiscriminado de hormônios são aceitos com certa resignação, uma vez que, simbolicamente, parecem significar o ingresso nessa 
identidade social em fabricação. Assim, o risco para a saúde dessas pessoas fica potencialmente aumentado.

A saída de casa foi relatada como consequência dos conflitos familiares devido à identidade de gênero e corroboraram os achados de outras pesquisas com pessoas em situação de rua ${ }^{\mathbf{1 4}, 15}$ e com travestis e mulheres trans em situação de prostituição $0^{11-13}$.

A gente passa a não se sentir bem, a família não fala nossa língua. A gente vai em busca de conhecimento e de liberdade. (Sabrina).

Sim, eu me afastei da família achando que eles não iam me aceitar. (Cleo).

Após a saída da casa da família, seguiu-se um período de itinerância em várias cidades, associado à prostituição, quando então foram morar em casas de cafetinas, pensões ou hotéis em zonas de prostituição, mediante pagamento de diárias:

Inclusive eu saí de casa, fui morar em outro lugar; igual fui pro no Rio de Janeiro. Me prostituí aqui em Belo Horizonte em duas casas de travesti. (Mila).

[...] e fui para São Paulo... e foi lá que eu vivi tudo ao limite, ao extremo... experimenta de tudo, foi onde eu adquiri HIV, fui presa, peguei dois tiros, tentaram me matar, e tudo que pode, do bom ao péssimo, eu vivi lá, entendeu? Mas de lá, eu consegui condições pra conhecer 18 estados do país. (Francis).

O pagamento de diárias enquanto forma de moradia é visto como muito arriscado, por que todos os dias é preciso pagar os valores da diária, sob pena de ficar sem teto ${ }^{12}$, o que foi constatado pelo presente estudo:

e o dinheiro já não dava pra suprir tudo, alimentação e tudo isso [...] a prostituta precisa ganhar, ela paga tudo muito mais caro, e ela paga tudo desde a manicure à lavagem e roupa. (Sabrina).
O uso de drogas e a prostituição apareceram de forma associada na fala das entrevistadas. Os gastos para comprar drogas e para manutenção cotidiana passaram a pesar e dificultaram o pagamento das diárias, provocando intermitência entre situação de rua e outras formas de se organizar:

Quando eu me meti com drogas, em são Paulo, é que eu fui conhecer a rua, porque eu já não estava dando conta de pagar mais as minhas dívidas. Eu cheguei a pagar dez reais numa diária e não conseguia pagar mais, porque eu queria usar uma droga, era cocaína [...] E quando eu vi, minha amiga tava debaixo da ponte, fui e lá eu fiquei, minha filha! Foi meu primeiro dia de rua ... e por fim tinha uma comunidade de travestis ali morando com seus homens. (Francis).

Foi observado que estar vivendo com HIV/ Aids aumentou o contexto das vulnerabilidades vividas. Dados do Ministério da Saúde apontaram que a prevalência de HIV entre mulheres trans e travestis é de $31,2 \%{ }^{16}$. Para as entrevistadas do presente estudo, a descoberta de estar vivendo com HIV causou grande impacto na vida delas:

Eu me descobri soropositivo e desisti um pouco de lutar pela vida, e foi quando eu comecei a perder tudo que eu tinha [...]. (Sabrina).

Quando eu adquiri o HIV, em 2007, eu tive tuberculose e H1N1, fiquei doente [...]. (Francis).

\section{b) Vida nas ruas}

Uma vez em situação de rua, as vulnerabilidades se agravaram diante das precariedades e violências relacionadas ao viver nas ruas:

A dificuldade de uma pessoa trans em situação de rua é a existência [...] sobreviver sem morrer com uma DST, um HIV Aids, ou um tiro, uma bala perdida, ou uma bala encontrada, ou o tráfico [... ] neste submundo, sobreviver na rua é uma luta diária, constante e dolorosa. (Sabrina). 
Morar na rua e ser trans é duas vezes mais preconceito. (Sandra).

No que se refere às violências que se manifestam em conflitos e agressões, várias situações foram relatadas, assim como nas pesquisas de Frangella ${ }^{\mathbf{1 7}}$ e Rosa ${ }^{\mathbf{1 8}}$ que evidenciaram a violência como um dos elementos intrínsecos ao universo das pessoas em situação de rua. No presente estudo, essas violências se concretizaram nas agressões e ameaças por agentes públicos, por outras pessoas em situação de rua e por pessoas desconhecidas, na exploração pelo próprio parceiro, bem como em situações de assassinato e ameaças de morte:

Eu tinha medo, eu tinha medo da noite, quando a gente ia chegar pra dormir, porque como era muito morador de rua, então já tinha acontecido situações de tentarem né, agredir morador de rua... chegou um cara lá falando que ia pôr fogo, aquele hippie que fica lá na frente na Praça da Savassi, e aí eu não tinha que fazer e tive que gritar que não era assim, vá queimar a sua maloca, a minha não. (Cleo).

[...] e tinha meu namorado que era um rapaz muito conhecido e respeitado na área, na redondeza. Eu sei que em SP eu fiquei dois anos na rua, mas sei lá, fiquei por que eu me sentia bem [...] mas aí, ainda tinha muito aquela ilusão, rua, noite, aquilo, aquilo outro... e ai eu fiquei lá, e só vim pra cá, porque esse meu namorado, nós voltamos e ele disse que ia me matar. (Francis).

Os dados da pesquisa do Projeto Trans apresentaram que o parceiro/namorado das travestis e transexuais entrevistadas foram apontados como agentes perpetradores em $37,9 \%$ das violências sofridas ${ }^{13}$. A pesquisa de $\mathrm{Rosa}^{18}$ revelou que várias mulheres sofreram violência física e ameaças praticadas pelos próprios parceiros de relacionamentos que começaram na rua.

A violência policial também foi relatada:
[...] chegou um policial botando todo mundo na parede. Eu perguntei: moço o que tá acontecendo? Ele me deu um chute assim no silicone aqui, só em mim... e silicone dói... dói pra colocar, dói pra vida toda. (Sandra).

Na pesquisa realizada por Kulick ${ }^{\mathbf{1 1}}$, as travestis entrevistadas foram unânimes em afirmar que os policiais militares são violentos e praticam muitos abusos. Também no Projeto Trans, a polícia é apontada como agente em $60 \%$ das violências sofridas ${ }^{13}$.

Nossas interlocutoras, indagadas se fazem denúncias das violências sofridas :

As travestis não buscam a delegacia da mulher por não acreditar, não denuncia por não acreditar ter justiça, que a justiça será feita e que os direitos serão garantidos. (Sabrina).

\section{c) Conhecimento e acesso aos servi- cos do SUS e Suas}

Segundo Mello et al. ${ }^{19}$, os problemas enfrentados pela população LGBT no que diz respeito ao acesso a serviços de saúde são particularmente mais dramáticos nos casos de travestis e transexuais, pois, além da reivindicação de atendimento especializado para demandas que não se colocam para outros segmentos populacionais, como alterações corporais associadas ao uso de hormônios e silicone, soma-se à transfobia institucional que incide sobre esse segmento populacional.

De modo geral, os achados deste estudo demonstraram que as entrevistadas conhecem, acessam ou são acessadas por vários serviços das redes SUS e Suas. Oito entrevistadas relataram conhecer e acessar algum serviço do SUS, desde acessos pontuais aos Centros de Saúde até acompanhamentos sistemáticos e especializados, além de episódios de internação hospitalar. Quanto ao acesso aos serviços do Suas, a maior parte referiu-se aos serviços específicos para a população em situação de rua. Entretanto, em ambas as redes, foram 
relatadas situações de violações de direitos a que estão submetidas no cotidiano dos serviços. Essas violações foram agrupadas e serão apresentadas como violência institucional, violência sexual e discriminação.

A violência institucional pode ser definida como aquela praticada nas instituições prestadoras de serviços públicos e é perpetrada por agentes que deveriam proteger os cidadãos garantindo-lhes uma atenção humanizada, preventiva e reparadora de danos ${ }^{20}$. Nesse contexto, destaca-se o desrespeito ao uso do nome social por parte dos funcionários. Embora o Decreto Presidencial $\mathrm{n}^{\circ} 8.727 / 2016^{21}$ oriente sobre o uso do nome social e o reconhecimento da identidade de gênero de travestis e transexuais no âmbito da administração pública federal, autárquica e fundacional, as entrevistadas identificaram avanços, mas também citaram situações e locais em que o nome social não foi respeitado.

A organização da oferta dos serviços em masculino e feminino e, consequentemente, o acolhimento institucional ou internação hospitalar a partir do sexo biológico se configuram como violência institucional na medida em que não respeitam a identidade de gênero da pessoa:

Quando eu cheguei em 2011, eu fui pra abrigo e eles me deram uma roupa masculina. Não respeitavam nome social, e os banheiro não tinha porta. Eu dei uma olhada assim, peguei minha mala, entreguei minha roupa na portaria e fui pra rua. (Sandra).

Nos hospitais, por não saber onde colocar essa travesti e a transexual, que aquelas que não importa eles colocam na ala masculina ainda. Então normalmente a gente fica no isolamento né? Fica num quarto sozinho, é o que tem acontecido comigo. Nem na ala masculina nem na feminina, fica na suíte isolada. (Sabrina).

A falta de privacidade e a precariedade dos banheiros coletivos nos abrigos institucionais foram relatadas por várias entrevistadas e apontadas como fatores que favorecem o assédio sexual:
A gente não tem assim uma privacidade de tomar um banho direito assim, tem um monte de homem, muito banheiro sem porta, aí quando tem [porta], cê entra e os outro fica assim esmurrando a porta pra gente sair. (Dafiny).

Uma vez um cara chegou em mim num abrigo e falou: eu estou indo tomar banho, vamos lá ficar comigo? E aí eu falei assim: se enxerga. e quando eu falei assim, 'se enxerga' eu fui e virei, ele só me deu um soco aqui que eu bati na coluna [pilastra do imóvel], aí abriu minha testa na hora. (Sandra).

Pois é, porque além da gente não querer, a gente é agredida por a gente não querer ser assediada, entendeu?. (Cleo).

A estratégia de uso do banheiro adaptado para pessoas com deficiência pelas travestis e mulheres trans oferecida por alguns serviços assim como a ocupação de quartos isolados em hospitais, embora permitam maior privacidade, devem ser vistas com cautela, pois despersonifica o sujeito, uma vez que, segundo $\mathrm{Scott}^{4}$, o gênero é um constituinte primário de nossas relações sociais.

A discriminação relacionada com a identidade de gênero se concretiza nas ruas e também dentro dos abrigos para mulheres, onde algumas das entrevistadas estavam acolhidas:

Até mesmo dentro da população em situação de rua, 30\%, 50\% não aceita a gente. Faz chacota. (Sabrina).

Eu tinha medo de não ser aceita [no abrigo], tinha constrangimento, medo do preconceito de ser criticado... ela olhou pra minha cara e falou eu odeio viado e negro, se revelou. (Sandra).

Nós temos uma ótima convivência com as muIheres, mas até hoje você pode ver que as vezes as mulheres chamam a gente de ele: 'ah não quero ficar no quarto com ele'. Aí a gente tem que pegar e falar: ele não querida, ela. (Mary). 
O grupo de iguais apareceu como estratégia para lidar com dificuldades vividas tanto nas ruas como nos serviços. O estar em grupo significa proteção, inclusive dos demais usuários, e uma forma de se fortalecerem para viabilizar suas demandas:

Se acontece alguma coisa, ela passa pra mim, se ela tiver preocupada, ela me fala; se eu fico dois dias fora, elas ficam loucas: cadê Mary?. (Mary).

Fico com os homossexuais, com os trans, com os travestis. (Mila).

Nós estamos todo dia junto. Todos os gays que dorme no quarto, nós só anda junto. Todo dia nós dormimos no mesmo quarto. O certo é cada um ir pra sua cama, só que nós pegamos o último quarto do corredor e se apossamos de lá, entramos prá lá e ficamos lá. (Dafiny).

Esses achados corroboram os da pesquisa do Projeto Trans ${ }^{13}$ e de Benedetti12 , diferentemente de Kulick ${ }^{\mathbf{1 1}}$, cuja pesquisa evidenciou relações de desconfiança e competitividade entre as travestis. Observou-se também um esforço por parte das entrevistadas de adequação às normas das instituições para serem aceitas e evitar conflitos:

Eles falam lá pra mim, que eu sou rainha do abrigo [...] eu fui elogiadíssima pelo novo diretor, porque em dez anos eu fui a única trans que não deu problema lá. Eu fiquei elogiado com isso, eu me comportei bem, mas eu fiz por onde né? (Sandra).

Tento lidar o melhor possivel com todo mundo, com os usuários com os funcionários, com os assistentes sociais, com os meninos [...] não sou uma pessoa de fazer confusão, de fazer coisa errada, sabe?. (Mila).

Como pontos positivos dos serviços, foram citados o respeito ao nome social, quando acontece, e a atitude de escuta e acolhimento de profissionais que foram nomeados como quem fez diferença na vida delas.
Não vou dizer que a assistente social não me ajudou, ela me ajudou sim, eu passei no Abrigo, na República, no Centro de Referência, me ajudou. Mas as pessoas lá dentro, como ser humano, agindo como ser humano, foi muito importante. (Francis).

[...] E ela conversa com você olhando dentro do seu olho, pra entender qual situação que você tá passando. E o bom é isso, você conversar olhando, a sinceridade é no olhar. (Sandra).

Rosa $^{18}$ encontrou resultados semelhantes com as mulheres pesquisadas que, ao relatarem experiências de sucesso na assistência e cuidado recebidos, tiveram como referência a atuação e o vínculo criado com profissionais específicos, e não ao trabalho das instituições que esses profissionais representam. Esses achados reforçam que a produção do cuidado e, consequentemente, a percepção de que ele acontece se baseiam, necessariamente, na perspectiva relacional entre sujeitos, entre profissionais e usuários ${ }^{3}$.

\section{d) Sugestões para qualificar os serviços}

As sugestões que mais se destacaram foram a importância do respeito ao nome social, a necessidade de maior privacidade nos ambientes que frequentam e também de serem ouvidas para a busca de melhorias nas ofertas de serviços:

Um modelo a gente ainda não tem, mas a gente tem que buscar o respeito ao nome social, à identidade de gênero. Uma das melhores formas, é ouvir esse público, que não é fácil ouvir. (Sabrina).

Sobre possíveis modelos para o serviço de acolhimento institucional, não houve consenso. Algumas posicionaram-se a favor da designação de quartos específicos para elas nos abrigos para homens: 
Eu acho que um quarto separado ficava melhor pra gente, pra não ter essa coisa que a gente assedia e o homem assediar a gente, a gente teria mais descanso né?? (Sandra).

A experiência em abrigos femininos também foi citada como positiva, sugerindo que o abrigamento seja feito em conjunto com mulheres cis: "Eu acho que funciona bem [abrigo para mulheres], nesta experiência, eu tô lá há oito meses" (Sandra). Outras sugeriram a criação de abrigos específicos para travestis e mulheres trans:

Mas eu vejo que viver travesti com travesti e transexuais com transexuais uma boa opção. (Sabrina).

Eu se acontecesse de ter uma casa ou um abrigo só pra trans, era uma coisa legal, tipo Casa Transvest. (Mary).

Ademais, há o entendimento da necessidade de capacitação dos profissionais para atendimento ao público trans e a contratação de pessoas trans para trabalhar nos diversos serviços é vista como forma de facilitar a aproximação e melhorar o atendimento:

Chega as abordagens de rua e não são totalmente preparados, os técnicos. Porque eles têm medo da violência das trans. Porque nós, no nosso sinônimo somos ruins. Mas nós não somos pessoas ruins. Nós só esperamos que as pessoas saibam conversar com a gente. (Sandra).

Colocando as entidades [organizações sociais que executam serviços para pessoas em situação de rua do Suas] para contratar, pessoa trans com trajetória de rua para trabalhar. (Sabrina).

Vamos colocar umas trans, pra abordar as trans no Abrigo, nos Cras [Centro de Referência de Assistência Social], dar chance pra pessoa escolher assim [por quem quer ser atendida]. De repente isso seria bom. (Francis).
A fala abaixo apresenta uma síntese tanto das demandas quanto de sugestões para as políticas públicas:

E eu acho que não basta acolher apenas a travesti e tirar ela da rua. Tem que tirar a rua dessa pessoa também, tem que capacitar essa pessoa pro mercado de trabalho, eu acho que por isso que tem que criar um olhar voltado para travestis e transexuais pra tirar a travesti [da rua], não é só dar uma comida, uma casa, tá entendendo? [...]. Um olhar específico para cada população, para cada pessoa, assim nem é população, é cada pessoa. (Sabrina).

\section{e) Empoderamento e perspectivas}

Empoderamento é um conceito multifacetado e envolve vários aspectos, tais como os cognitivos, afetivos e de conduta ${ }^{22}$. Segundo Baquero $^{\mathbf{2 3}}$, o empoderamento individual se refere ao aumento da capacidade dos indivíduos de se sentirem influentes nos processos que determinam suas vidas, enquanto o empoderamento comunitário envolve um processo de capacitação de grupos ou indivíduos desfavorecidos para a articulação, conquista e defesa de seus interesses e de direitos de cidadania e para influenciar ações do Estado.

Várias foram as falas sobre a importância de se afirmarem como trans, de conhecerem e darem visibilidade aos próprios direitos, além de se unirem para fazer conquista:

Você tem que mostrar bem o que sabe, que é resolvida no que você quer, pra poder viver. (Sandra).

Eu falei assim: tudo bem que vai me encaminhar pro Hospital, mas olha aqui, vai ter que levar no meu relatório que eu sou uma mulher transexual e que eu não quero ir pra ala masculina. (Sabrina).

É, eu penso assim, que se a gente não se unir a gente nunca vai mudar nada. (Sandra). 
Em primeiro lugar deveria ter alguns cartazes espalhados nos serviços sobre o homossexualismo, sobre trans, pra muitas pessoas tá se informando, saber que é um crime fazer brincadeira, piadinha, coisa sem graça com a gente. (Dafiny).

Muitas expressaram o desejo de ter oportunidades de trabalho:

O meu futuro é terminar o curso agora em março. Eu preciso estar ocupada. A gente precisa muito de trabalho, é de trabalhar mesmo, que é uma das coisas mais difíceis pra gente. (Cleo).

Eu acho importante é você fomentar isso até para as suas amigas, falar que é importante a presença, não do homossexual, porque existe muito homossexual, mas da trans, da travesti [no mercado de trabalho], porque às vezes as pessoas tão por aí, precisando. (Francis).

Não existem dados oficiais sobe a inserção de travestis e transexuais no mercado de trabalho. De acordo com Pelúcio²4, a carência de alternativas em relação ao mundo do trabalho tem feito da prostituição um destino, mais que uma possibilidade de escolha.

Uma das entrevistadas aposta na sua atitude ativa para mudar os estereótipos que a sociedade tem sobre as travestis:

Tanto é que meu amigo, vem aqui... Eu ligo pra ele, mudei a opinião dele, tá... Eu não vou formar mais a opinião dele, porque já tá formada, mas eu vou formar a do filho dele, quando o filho dele crescer, acredito eu né? O que a gente não faz por essa geração a gente faz pela próxima. (Francis).

Estas falas traduzem um conjunto de desejos e pontos de vista que se correlacionam com a perspectiva de empoderamento tanto individual como comunitário. Entretanto, há ainda um longo caminho a ser percorrido, uma vez que, a participação social de travestis e transexuais no Brasil é caracterizada por grande dificuldade de organização e articulação e, consequentemente, pouca visibilidade dentro do próprio movimento LGBT. Fundamentam esse contexto as prioridades, como a própria sobrevivência, decorrentes das diversas formas de exclusão vivenciadas por esse grupo ${ }^{25}$.

\section{Considerações finais}

As dificuldades encontradas para acessar o público-alvo desta pesquisa evidenciaram ser necessário aproximação e construção de relações de confiança, exigindo do pesquisador disponibilidade para se inserir nos diversos contextos em que as entrevistadas vivem.

Este estudo demonstrou que a situação de rua para as travestis e para as mulheres trans é resultado de um conjunto de vulnerabilidades e violações que vão se somando ao longo de suas trajetórias de vida. Foi possível identificar momentos críticos, passíveis de intervenções pelo poder público, relacionados tanto com a ida para as ruas quanto com a promoção e a garantia de direitos básicos para aquelas que já se encontram nessa situação.

Sugerem-se investimentos em ações que visem ao fortalecimento dos vínculos familiares e comunitários, com possíveis intervenções nas questões que geram conflitos familiares e que, potencialmente, levam à saída de casa. A chamada segurança da vivência familiar ou a segurança do convívio é uma das proteções que a Política de Assistência Social se propõe a afiançar por meio do fortalecimento da função protetiva da família, visando prevenir rupturas de vínculos e situação de riscos relacionados com vários motivos, entre eles, por discriminações de gênero e identidade sexual ${ }^{\mathbf{2}, 26}$. Nesse contexto, destaca-se também o desafio para as políticas direcionadas para a juventude 27 alcançarem essas jovens, a fim de favorecer o desenvolvimento de autonomia e posicionamento afirmativo em seus contextos familiares e comunitários. Além disso, a oferta de políticas e programas de formação profissional podem criar alternativas à prostituição e promover a inserção qualificada no mercado de trabalho. 
No que tange ao acesso universal e igualitário à saúde, prescritos pela Constituição Federal de 1988, assim como a garantia da integralidade da assistência com equidade e livre de preconceitos e privilégios ${ }^{28}$, esta pesquisa expõe lacunas nos atendimentos que vulnerabilizam a saúde desse grupo populacional invisível e discriminado. A ausência de acompanhamento multiprofissional para os processos de transição aponta para a necessidade de disponibilização e garantia de acesso a esses serviços públicos especializados, assim como aos serviços e ações de orientação e tratamento sobre uso prejudicial de drogas, bem como de prevenção e tratamento de Doenças Sexualmente Transmissíveis (DST) e HIV/ Aids. Também se faz necessário oferta de serviços públicos para atendimento à saúde integral de travestis e de mulheres trans vítimas de violências a fim de favorecer o desenvolvimento da autonomia, do protagonismo e da participação social.

Evidenciou-se que as entrevistadas conhecem e acessam vários serviços das redes do SUS e do Suas. Entretanto, esses serviços não estão alinhados às suas necessidades específicas e, assim, produzem e reproduzem violências por meio de regras e normas de funcionamento. A violência institucional provoca sofrimentos e desproteção e deve ser combatida por intermédio da oferta de espaços dignos, que respeitem efetivamente a identidade de gênero, com revisão democrática das regras e considerando o tempo dos sujeitos. Para tal, são imprescindíveis investimentos em educação permanente para os profissionais e usuários dos serviços, a fim de favorecer uma convivência com respeito entre os diferentes, assim como o acesso à informação e à formação em direitos humanos para as travestis e as mulheres trans. Essa natureza de formação é essencial para a promoção da cidadania trans, pois pode favorecer a condição de fazer escolhas e o empoderamento para fazer denúncias.

Pode-se dizer que a invisibilidade das violências em que vivem e estão submetidas é reflexo da ausência de dados oficiais sistemáticos e atualizados sobre esse público, assim como da inexistência de marcos legais para a responsabilização dos agentes perpetradores. Dessa forma, é necessário estabelecer mecanismos para a quebra desse ciclo de violências em que ainda é comum as vítimas serem responsabilizadas pelas agressões que sofrem.

Os achados do presente estudo demonstraram a existência de uma rede de solidariedade entre elas, tanto nas ruas como nos serviços, que funciona como estratégia de resistência e enfrentamento diante de contextos marginalizados. $\mathrm{O}$ reconhecimento da existência de uma rede de comunicação, cumplicidade e vínculos afetivos entre as pesquisadas é um ponto importante a ser explorado como estratégia na construção de metodologias para o atendimento dessa população pelos serviços públicos.

À guisa de conclusão, pode-se afirmar que os achados deste estudo orientam que as intervenções para a promoção e proteção social de travestis e de mulheres trans em situação de rua deverão envolvê-las ativamente no desenvolvimento das propostas e que as abordagens devem ser personalizadas considerando as singularidades dos sujeitos. Essas demandas extrapolam as políticas de saúde e de assistência social, o que exige um esforço de gestão intersetorial para ofertas coordenadas e articuladas de serviços e ações.

\section{Colaboradores}

Mendes LG (0000-0002-3311-5440)* contribuiu para a concepção e planejamento do estudo, realizou a coleta, análise e interpretação dos dados, escrita e aprovação final do manuscrito. Jorge AO (0000-0003-1366-1732)* e Pilecco FB (0000-0001-8316-8797)* contribuíram para o delineamento do estudo, análise e interpretação dos dados, revisão crítica e aprovação final do manuscrito.
*Orcid (Open Researcher and Contributor ID). 


\section{Referências}

1. Yazbek MC. A política social brasileira nos anos 90: a refilantropização da Questão Social. São Paulo: Abong; 1995.

2. Brasil. Secretaria Nacional de Assistência Social. Política Nacional de Assistência Social. Brasília, DF: Ministério do Desenvolvimento Social; 2004.

3. Merhy EE. O ato de cuidar: a alma dos serviços de saúde. In: Brasil. Ministério da Saúde, Secretaria de Gestão do Trabalho e Educação na Saúde, Departamento de Gestão da Educação na Saúde [internet]. Brasília, DF: Ministério da Saúde; 2004 [acesso em 2017 jun 19]. Disponível em: https://www.nescon. medicina.ufmg.br/biblioteca/imagem/2103.pdf.

4. Scott J. Gênero: uma categoria útil de análise histórica. Rev Educ Realidade [internet]. 1995 [acesso em 2017 out 2]; 20(2): 71-99. Disponível em: http:// seer.ufrgs.br/index.php/educacaoerealidade/article/ view/71721/40667. Acesso em 02 out 2017.

5. Bento BAM. O que é transexualidade. São Paulo: Brasiliense; 2008.

6. Prado MA, Junqueira RD. Homofobia, hierarquização e humilhação social. Diversidade Sexual e Homofobia no Brasil. São Paulo: Fundação Perseu Abramo; 2011.

7. Silva MLL. Trabalho e população em situação de rua no Brasil. São Paulo: Cortez; 2009.

8. Foucault M. Vigiar e punir: nascimento da prisão. 37. ed. Petrópolis: Vozes; 2009.

9. Natalino MAC. Texto para discussão no 2246. Estimativa da População em Situação de Rua no Brasil. [internet]. Brasília, DF: Instituto de Pesquisa Econômica; 2016. [acesso em 2017 jun 25]. Disponível em: https:// www.ipea.gov.br/portal/index.php?option=com_ content\&view $=$ article $\&$ id $=28819$.

10. Bardin L. Análise de conteúdo. Lisboa: Edições 70; 2016.
11. Kulick D. Travesti: prostituição, sexo, gênero e cultura no Brasil. Rio de Janeiro: Fiocruz; 2008.

12. Benedetti MR. Toda feita: o corpo e o gênero das travestis. Rio de Janeiro: Garamond; 2005

13. Núcleo de Direitos Humanos e Cidadania LGBT, UFMG (NUH-UFMG). Direitos e violência na experiência de travestis e transexuais na cidade de Belo Horizonte: Construção de um perfil social em diálogo com a população [internet]. 2016 [acesso em 2017 jun 7]. Disponível em: http://www.nuhufmg.com.br/ gde_ufmg/index.php/projeto-trans.

14. Brasil. Relatório sobre violência homofóbica no Brasil: ano de 2013. Brasília, DF: Secretaria de Direitos Humanos; [internet]. 2016. [acesso em 2017 jun 7]. Disponível em: http://www.direito.mppr.mp.br/arquivos/ File/RelatorioViolenciaHomofobicaBR2013.pdf.

15. Garcia F, Souza RA, Brito CMD, et al, organizadores. Terceiro censo da população de rua do município de Belo Horizonte. Viçosa: Suprema; 2014.

16. Brasil. Ministério da Saúde. Relatório de Monitoramento Clínico do HIV. Brasília, DF: Ministério da Saúde, Secretaria de Vigilância em Saúde; 2016

17. Frangela S. Corpos urbanos errantes: uma etnografia da corporalidade de moradores de rua em São Paulo. São Paulo: Fapesp; 2009.

18. Rosa AS. Mulheres em situação de rua na cidade de São Paulo: um olhar sobre trajetórias de vida [tese]. São Paulo: Universidade Federal de São Paulo; 2012.

19. Mello L, Brito W, Maroja D. Políticas públicas para a população LGBT no Brasil: notas sobre alcances e possibilidades. Cad Pagu [internet]. 2012 [acesso em 2017 jun 19]; 39(1):403-29. Disponível em: http:// www.scielo.br/scielo.php?script=sci_arttext\&pid $=$ S0104-83332012000200014.

20. Minayo MCS. Violência e Saúde. Rio de Janeiro: Fiocruz; 2006. 
21. Brasil. Decreto $\mathrm{n}^{\circ} 8.727$ de 28 de abril de 2016. Uso do nome social e o reconhecimento da identidade de gênero de pessoas travestis e transexuais no âmbito da administração pública federal direta, autárquica e fundacional [internet]. Diário Oficial da União. 28 Abr 2016. [acesso em 2020 fev 10]. Disponível em: https://www2.camara.leg.br/legin/fed/decret/2016/ decreto-8727-28-abril-2016-782951-publicacaooriginal-150197-pe.html.

22. Lopes AAF. Cuidado e empoderamento: a construção do sujeito responsável por sua saúde na experiência do diabetes. Saúde Soc. 2015; 24(2):486-500.

23. Baquero RVA. Empoderamento: instrumento de emancipação Social? Uma discussão conceitual. Rev Debates. 2012; 6(1):173-87.

24. Pelúcio L. Abjeção e desejo: uma etnografia travesti sobre o modelo preventivo de AIDS. São Paulo: Annablume, Fapesp; 2009.

25. Pedra CB. Acesso a cidadania por travestis e transexuais no Brasil: um panorama da atuação do Estado no enfrentamento das exclusões [dissertação]. Belo Horizonte: Fundação João Pinheiro, Escola de Governo Professor Paulo Neves de Carvalho; 2018. 274 p.
26. Conselho Nacional de Assistência Social. Resolução $\mathrm{n}^{\mathrm{o}} 109$ de 2009 de 11 de novembro de 2009. Aprova a Tipificação Nacional de Serviços Socioassistenciais [internet]. Diário Oficial da União. 2009 Nov 11. [acesso em 2020 jan 10]. Disponível em: http://www. mds.gov.br/cnas/viii-conferencia-nacional/manual-orientador/legislacao_resolucao-cnas-109-2009.pdf/ download.

27. Brasil. Guia de Políticas Públicas de Juventude Brasília, DF: Secretaria-Geral da Presidência da República; 2006.

28. Brasil. Lei no 8.080 de 19 de setembro de 1990. Dispõe sobre as condições para a promoção, proteção e recuperação da saúde, a organização e o funcionamento dos serviços correspondentes e dá outras providências [internet]. Diário Oficial da União. 1990 set 19. [acesso em 2020 fev 20]. Disponível em: http:// www.planalto.gov.br/ccivil_03/leis/L8080.htm.

Recebido em 10/04/2019

Aprovado em 03/10/2019

Conflito de interesses: inexistente

Suporte financeiro: não houve 